\title{
Comparison of Contractile Effects of Sodium Vanadate and Ouabain in Vascular Smooth Muscles of Guinea-pigs and rats
}

\author{
Tomoko Shimada, Akio Tsuji, Keiichi Shimamura \\ and Satoru SunANo \\ Research Institute of Hypertension, Kinki University, Sayama-cho, Osaka, Japan
}

\begin{abstract}
Shimada, T., Tsuji, A., Shimamura, K. and Sunano, S. Comparison of contractile effects of sodium vanadate and ouabain in vascular smooth muscle of guinea-pig and rats. Japanese Journal of Smooth Muscle Research, 1986, 22(5) ; 409-422_-Ouabain and vanadate are known as potent inhibitors of $\mathrm{Na}, \mathrm{K}$-ATPase in various tissues including smooth muscles. Both agents showed contractile action on various smooth muscles in a similar fashion: stronger contractile action on the aortae of rats (WKY and stroke prone spontaneously hypertensive rats, SHRSP) and guinea-pigs, and weaker contractile actions on basilar and mesenteric arteries of the same animals. Time to peak tension, however, was far longer in ouabain-induced contraction. Phentolamine depressed ouabain-induced contractions, while vanadate-induced contractions were not affected. Elevation of $\mathrm{K}^{+}$ concentration to 20 or $30 \mathrm{mM}$ potentiated vanadate-induced contraction markely, while it potentiated ouabain-induced contraction only slightly. DIDS blocked vanadate-induced contraction but showed no effect on ouabain-induced contraction. Removal of Ca abolished ouabain-induced contractions, while vanadate-induced contractions of reduced height could be observed in the absence of Ca. Verapamil depressed both ouabain- and vanadateinduced contractions of WKY and SHRSP aorte aut exhibited no effect on the guinea-pig aorta. Thus, although similarities of the action of ouabain and sodium vanadate were observed, the modes of the actions were revealed to be different in the two agents. Inhibition of $\mathrm{Na}, \mathrm{K}$-ATPase might be involved in the case of ouabain-induced contractions, and inhibition of $\mathrm{Ca}$-ATPase of membranous systems might be involved in vanadate-induced contraction.
\end{abstract}

Key words: Vanadate, Ouabain, Na, K-ATPase, Vascular Smooth Muscles.

\section{Introduction}

Vanadate has been recognized as a potent inhibitor of $\mathrm{Na}, \mathrm{K}$-ATPase, since it was found in muscle (Josephson and Cantley, 1977; Cantley et al., 1977). It inhibits Na, K-ATPase or $\mathrm{Na}, \mathrm{K}$-pump of smooth muscles, as has been demonstrated directly or indirectly (Grover et al., 1980 ; Ueda et al., 1982 ; Searle et al., 1983 ; Ueda and Urakawa, 1983). The inhibition of Na, 
$\mathrm{K}$-ATPase induces contractions of vascular smooth muscles, as has been reported mostly in experiments which were performed using ouabain treatment (Broekart and Godfraind, 1973 ; Karaki and Urakawa, 1977 ; Karaki et al., 1978; Ozaki et al., 1978; Toda, 1980 ; Palaty, 1980 ; Nilson and Mulvany, 1981 ; Moreland et al., 1984 ; Ishida et al., 1985). In these reports, it was revealed that the efficiency of ouabain in initiating contraction varies among types of vascular smooth muscles. In addition, it has been reported that ouabain at concentrations up to $10^{-2} \mathrm{M}$ did not cause contraction in rat resistance vessels (Mulvany et al., 1882 ; Mulvany et al., 1984 ; Aalkjaer and Mulvany, 1985). Modes of ouabain action on vascular smooth muscles are also different among types of vascular tissues: direct action on vascular smooth muscles and indirect action through the release of intrinsic neurotransmitters, roles of $\mathrm{Ca}$ in the initiation of contraction, etc.

Vanadate has also been reported to induce contractions of vascular smooth muscles (Huot et al., 1979; Ozaki and Urakawa, 1980; Rapp, 1981). We have recently reported that the efficiency of vanadate in the initiation of contraction varied among types of vascular smooth muscles (Shimada et al., 1986). These variations seemed to be similar to those in the action of ouabain mentioned above.

Therefore, the present experiments were performed to compare the effects of vanadate and ouabain and also some modes of their actions in vascular smooth muscles of guinea-pigs and rats.

\section{Methods}

Guinea-pigs $(519 \pm 20.3 \mathrm{~g}$, mean $\pm \mathrm{SE}, \mathrm{n}=18)$, Wistar Kyoto rats (WKY, $249 \pm 4.1 \mathrm{~g}$, mean \pm $\mathrm{SE}, \mathrm{n}=12$ ) and stroke prone spontaneously hypertensive rats (SHRSP, $245 \pm 7.7 \mathrm{~g}$, mean $\pm \mathrm{SE}$, $\mathrm{n}=21$ ) were used in the present experiments. The systolic blood pressures of WKY and SHRSP, measured by the tail cuff method, were $133 \pm 2.5 \mathrm{mmHg}$ (mean $\pm \mathrm{SE}, \mathrm{n}=12$ ) and $216 \pm$ $4.5 \mathrm{mmHg}$ (mean $\pm \mathrm{SE}, \mathrm{n}=16$ ), respectively. Animals were anaesthetized with ether and killed by bleeding from the carotid artery. Aortae, mesenteric arteries of all animals and basilar arteries of guinea-pigs were dissected, and fat and connective tissues were removed carefully in modified Tyrode's solution. From these aortae and arteries, spiral cut preparations were made under a dissecting microscope. The widths of the aortae, mesenteric artery and basilar artery preparations were about $1.0 \mathrm{~mm}, 0.2 \mathrm{~mm}$ and $0.1 \mathrm{~mm}$, respectively. These preparations were incubated in organ baths of $10 \mathrm{ml}$ filled with modified Tyrode's solution of the following composition: $\mathrm{NaCl}, 137 \mathrm{mM}$; $\mathrm{KCl}, 2.7 \mathrm{mM}$; $\mathrm{CaCl}_{2}, 2.0 \mathrm{mM} ; \mathrm{MgCl}_{2}, 1.0 \mathrm{mM} ; \mathrm{NaHCO}_{3}, 11.9$ $\mathrm{mM} ; \mathrm{NaH}_{2} \mathrm{PO}_{4}, 0.4 \mathrm{mM}$; glucose, $5.6 \mathrm{mM}$, equilibrated with a gas mixture of $95 \% \mathrm{O}_{2}$ and $5 \%$ $\mathrm{CO}_{2}$. K-Tyrode's solution was made by replacing all $\mathrm{NaCl}$ of modified Tyrode's solution with $\mathrm{KCl}$, and elevated K-Tyrode's solutions were made by mixing the modified and K-Tyrode's solution to obtain the desired $\mathrm{K}$-concentrations. Ca-free Tyrode's solution was made by omitting $\mathrm{CaCl}_{2}$ of the modified Tyrode's solution. No correction of changes in osmolarity due to the omission of $\mathrm{CaCl}_{2}$ was made, since no obvious effect on contractile responses was observed by similar changes in osmolarity made by the reduction of $\mathrm{NaCl}$ (Sunano, unpublished observation). The temperature of the solution was kept at $36^{\circ} \mathrm{C}$ by circulating water of the same temperature in the outer chamber of the organ bath. The temperature of circulating 
water was controlled by a thermoregulator (Yamato, Tokyo). The $\mathrm{pH}$ of the modified Tyrode's solution at this temperature was between 7.2 and 7.3 .

Changes in tension were measured isometrically by force displacement transducers (Shinkoh, U-gage, Tokyo) and recorded by a thermal-pen recorder (San-ei Sokki).

The experiments were always started from the repetition of $\mathrm{K}$-contracture, which was induced by changing the incubation medium from the modified Tyrode's solution to K-Tyrode's solution. The durations and interval of the application of K-Tyrode's solution varied among the preparations since the time to peak tension and relaxation time varied. The contraction heights increased by the repetition and achieved maximum by 4 to 5 times repetition. The height of the fifth $\mathrm{K}$-contracture was treated as the control $\mathrm{K}$-contracture height, and most of the drug-induced contractions were expressed as percentages of the contraction heights of the respective preparations.

Drugs used in the present experiments were: sodium metavanadate $\left(\mathrm{NaVO}_{3}, \mathrm{Wako}\right.$, Osaka), ouabain (Sigma), phentolamine (Ciba), 4, 4' -diisothiocyano-2, 2'-disulfonic acid stilbene (DIDS, Wako, Osaka), and verapamil (Ei-sai).

For statistical evaluation, Student's t-test was employed and was considered significant when p value was smaller than 0.05 .

\section{Results}

1. Comparison of contractile actions of sodium vanadate and ouabain in various vascular smooth muscles.

Fig. 1 shows the contractile responses of the aorta, mesenteric artery and basilar artery of guinea-pig to $1 \mathrm{mM}$ sodium vanadate. This concentration $\left(10^{-3} \mathrm{M}\right)$ was chosen because it was just submaximal in most of the preparations, regardless of the variation of the maximum response (Shimada et al., 1986). As shown in this figure, the heighest contractile response was observed in the aorta, but it was still lower than the height of $\mathrm{K}$-contracture. Both in the mesenteric and basilar arteries, the contractile responses to sodium vanadate were extremely low as compared with those to $\mathrm{K}$-Tyrode's solution ( $\mathrm{K}$-contracture). By washing out vanadate with modified Tyrode's solution, the developed tension returned to the initial level within 10 to

Fig. 1. Effects of sodium vanadate on various vascular smooth muscles of the guineapig. $\mathrm{a}, \mathrm{m}$ and $\mathrm{b}$ indicate aorta, mesenteric artery and basilar artery, respectively. Sodium vanadate $\left(\mathrm{NaVO}_{3}, 10^{-3} \mathrm{M}\right)$ was applied after the observation of $\mathrm{K}$ Tyrode's solution ( $\mathrm{K}-\mathrm{T}$ )-induced contracture. Downward arrows indicate the washing out with modified Tyrode's solution.

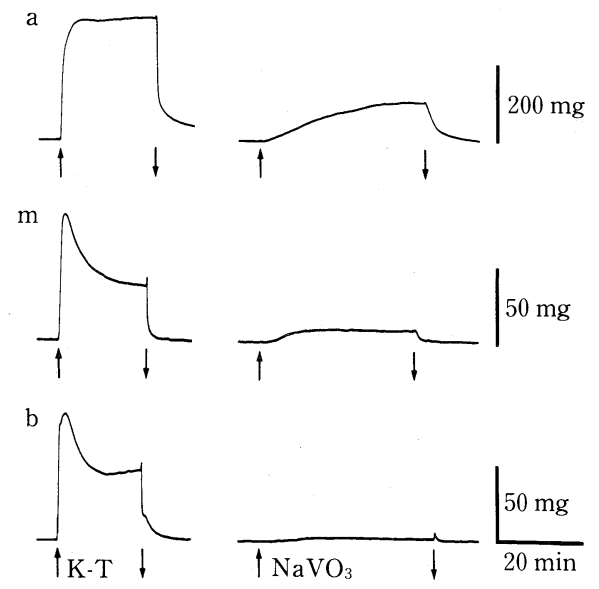




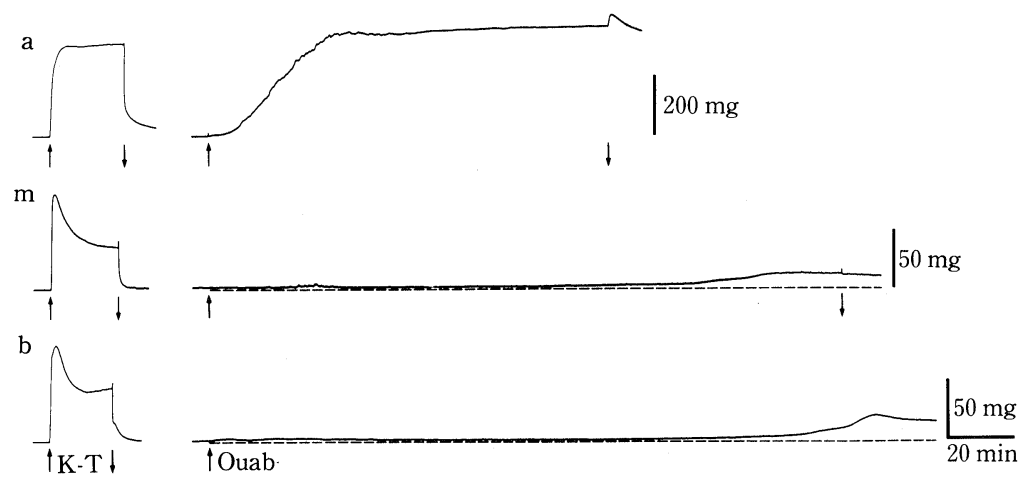

Fig. 2. Ouabain-induced tension developments in various vascular smooth muscles of the guinea-pig. Ouabain of $10^{-4} \mathrm{M}$ (Ouab) was applied in this experiment. $\mathrm{K}-\mathrm{T}$, the application of $\mathrm{K}$-Tyrode's solution. $\mathrm{a}, \mathrm{m}$ and $\mathrm{b}$ indicate the same as those in Fig. 1.

20 minutes.

Similar results were obtained in the aortae and mesenteric arteries of WKY and SHRSP. The rates of tension development and peak tensions of aortae of these aimals were significantly greater than those of the guinea-pig aorta.

Contractile effects of ouabain were also studied. As shown in Fig. 2, 10 $0^{-4} \mathrm{M}$ ouabain induced marked tension development which is comparable to or higher than that of $\mathrm{K}$ contracture in the guinea-pig aorta. In the mesenteric and basilar artery, on the other hand, no obvious tension development could be observed up to 120 minutes of application in most of the preparations. When the application period was prolonged further, gradual tension developments, which achieved their maxima at 180 to 200 minutes after the application, could be observed. However, the developed tensions were far smaller when compared with those of $\mathrm{K}$ contracture. The recovery process after the washing out of ouabain were also slow, and at least 120 minutes were required to achieve complete relaxation.

In aortae of WKY and SHRSP, ouabain of $10^{-3} \mathrm{M}$, which was 10 times higher than the concentration used in the guinea-pigs, induced initial small tension development followed by a second elevation of tension. The sceond contractions achieved their maxima at 90 to 120 minutes after the application of ouabain, and they were smaller than those of $\mathrm{K}$-contracture. In the mesenteric artery of WKY, no tension development could be observed even 300 minutes after the application of $10^{-3} \mathrm{M}$ ouabain, while weak but significant tension development could be observed in the mesenteric artery of SHRSP. These comparative results were summarized in Fig. 3 and Table 1.

As shown in Fig. 3, the contractile response to sodium vanadate and ouabain varied among the types of blood vessels in a similar fashion: it was larger in the aortae and smaller in the other blood vessels. When both contractions were compared, vanadate-induced contractions were greater in WKY and SHRSP blood vessels and smaller in guinea-pig blood vessels. It should also be mentioned that in WKY and SHRSP blood vessels, ouabain of 10 times higher concentration than that used in the guineapig blood vessels was used in the present experiments.

A greater differece in the action of vanadate and ouabain was observed in the time to peak 


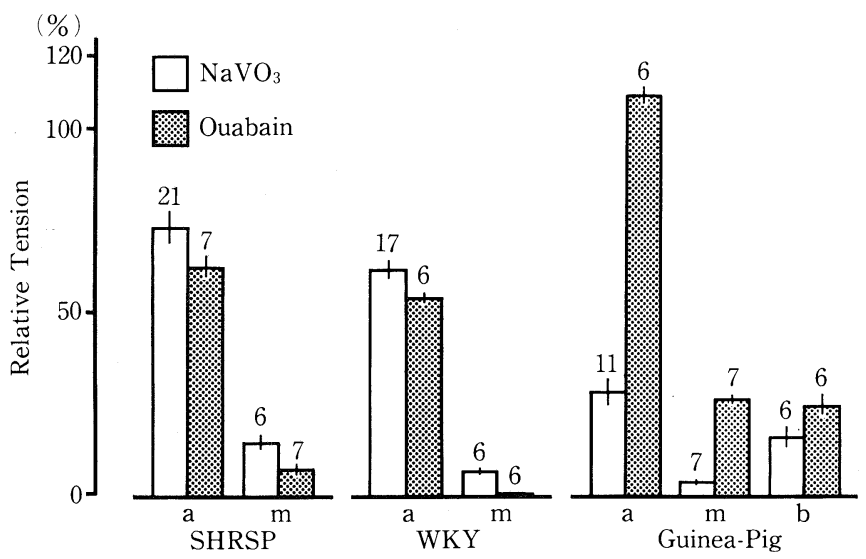

Fig. 3. Heights of sodium vanadate- and ouabain-induced contractions in various vascular smooth muscles of different animals. Control K-Tyrode's-induced contracture heights were taken as 100 percent, and each contraction height was expressed as percentages of these hights with SEs (vertical bars). Numbers at the top of each column indicate the number of respective experiment. Sodium vanadate $\left(\mathrm{NaVO}_{3}\right)$ of $10^{-3} \mathrm{M}$ in all animal species, ouabain of $10^{-3} \mathrm{M}$ in SHRSP and WKY and $10^{-4} \mathrm{M}$ in the guinea-pig, were, respectively, used. $\mathrm{a}, \mathrm{m}$ and $\mathrm{b}$ indicate the same as Fig. 1.

tension (Table 1). Vanadate-induced contractions attained their maxima within 30 minutes after the application in the majority of preparations, whereas at least 100 minutes were required to achieve the peak in ouabain-induced contraction. In the mesenteric artery of SHRSP, for example, it took 240 minutes to reach peak tension, in contrast to 37 minutes in the case of vanadate-induced contraction. Moreover, no tension development was observed in the mesenteric artery of WKY within $300 \mathrm{~min}$ utes after the application of ouabain, as described above.

Effects of phentolamine on ouabain- and sodium vanadate-induced contraction were studied since the involvements of noradrenaline release in the ouabain-induced contraction have been presented, as will be mentioned in the discussion. Aortae of WKY, SHRSP and guinea-pigs were used in these experiments, as they showed greater contractile responses to both ouabain and sodium vanadate. In these aortae, phentolamine of $5 \times 10^{-5} \mathrm{M}$ completely blocked $10^{-6} \mathrm{M}$ noradrenaline-induced contraction. However, phentolamine of the same concentration showed no effect on sodium vanadate-induced contraction of all aortae (Fig. 4). Ouabain-induced contractions, on the other hand, were significantly depressed by the treatment with phentolamine of the same concentration (Fig. 4). 

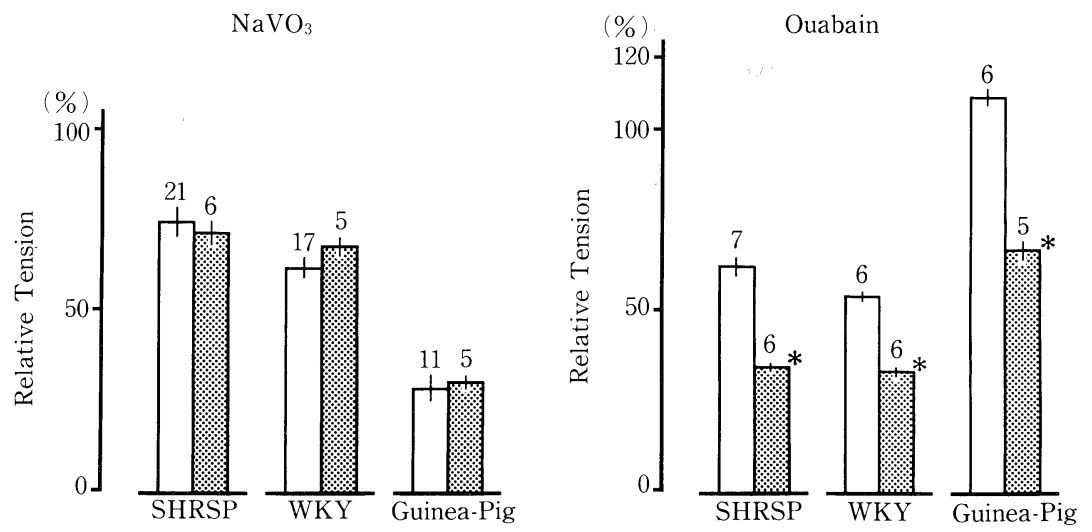

Fig. 4. Heights of sodium vanadate- and ouabain-induced contractions of aortae in the presence of phentolamine. Heights of respective $\mathrm{K}$-contracture were taken as 100 percent, and each contraction height was expressed as a percentage of this height with SEs (vertical bars). Phentolamine of $5 \times 10^{-5} \mathrm{M}$ was applied 10 minutes before the application of either drug. Sodium vanadate $\left(\mathrm{NaVO}_{3}\right)$ of $10^{-3} \mathrm{M}$ was used in all the preparations. Concentrations of ouabain used were $10^{-3} \mathrm{M}$ in SHRSP and WKY aortae and $10^{-4} \mathrm{M}$ in guinea-pig aortae. Open columns, control sodium vanadate- or ouabain-induced contractions. Stippled columns, contraction heights in the presence of phentoloamine. Numbers at the top of each column indicate the number of respective experiment. Asterisks indicate significant differences from control $(\mathrm{p}<0.001)$.

\section{Effects of increased $K$-concentration and DIDS.}

Vanadate-induced contractions of mesenteric arteries of all animal species were extremely small, as described above. The vanadate-induced contractions of mesenteric arteries were potentiated markedly in the presence of 20 to $30 \mathrm{mM} \mathrm{K}^{+}$(Figs. 5 and 6). In the mesenteric artery of SHRSP shown in Fig. 5, $20 \mathrm{mM} \mathrm{K}$ caused slight and $30 \mathrm{mM}$ K caused more marked increase in the basal tension. The addition of $1 \mathrm{mM}$ sodium vanadate in the presence of elevated $\mathrm{K}^{+}$caused slow but marked tension development up to about $60 \%$ of the hegiht of $\mathrm{K}$ contracture.

Ouabain induced no tension development in the mesenteric artery of SHRSP within the application period of 30 minutes (Fig. 5). In the presence of $20 \mathrm{mM} \mathrm{K}^{+}$, it induced a quick elevation of tension which was sustained for at least 30 minutes. Ouabain-induced tension development was more potentiated in the presence of $30 \mathrm{mM} \mathrm{K}^{+}$. However, it became transient and relaxed toward the level before the application. The potentiation of sodium vanadate- and ouabain-induced contraction could also be observed in the guinea-pig mesenteric artery, as summarized in Fig. 6.

Thus, although the elevation of $\mathrm{K}^{+}$concentration to 20 or $30 \mathrm{mM}$ potentiated both sodium vanadate-and ouabain-induced contractions, the mode of and the degree of the potentiation were different between these two contractions.

In the depolarized preparation of the guinea-pig mesenteric artery soaked in K-Tyrode's solution, sodium vanadate showed dual action which was composed of the first transient contractile and the second marked relaxing actions (Fig. 7). Thus almost complete relaxation was brought about by $10^{-3} \mathrm{M}$ sodium vanadate. Ouabain $\left(10^{-4} \mathrm{M}\right)$, on the other hand, showed 
no relaxing but sustained contractile action on the K-Tyrode's solution depolarized mesenteric artery of the guinea-pig (Fig. 7). In WKY and SHRSP mesenteric arteries, no relaxing but only contractile response was observed by the application of the same concentration of sodium vanadate, as has previously been reported (Shimada et al., 1986).

Aortae of all animal species also showed relaxing response to sodium vanadate preceded by initial transient contractile response. Unlike its action in the guinea-pig mesenteric artery,
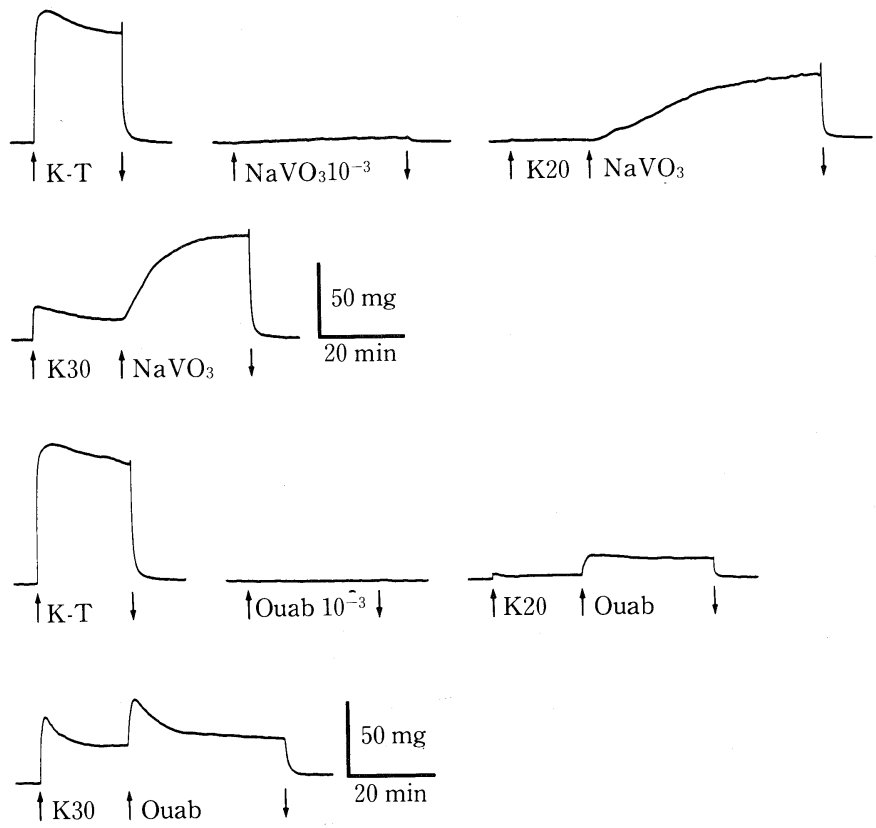

Fig. 5. Effects of elevation of $\mathrm{K}^{+}$concentration on sodium vanadate- and ouabain-induced contractions in SHRSP mesenteric artery. $\mathrm{K}^{+}$concentration was elevated to $20 \mathrm{mM}$ (K20) or to 30 $\mathrm{mM}$ (K30) 21 minutes before the application of sodium vanadate $\left(10^{-3} \mathrm{M}\right.$, upper figures) or ouabain $\left(10^{-3} \mathrm{M}\right.$, lower figures).

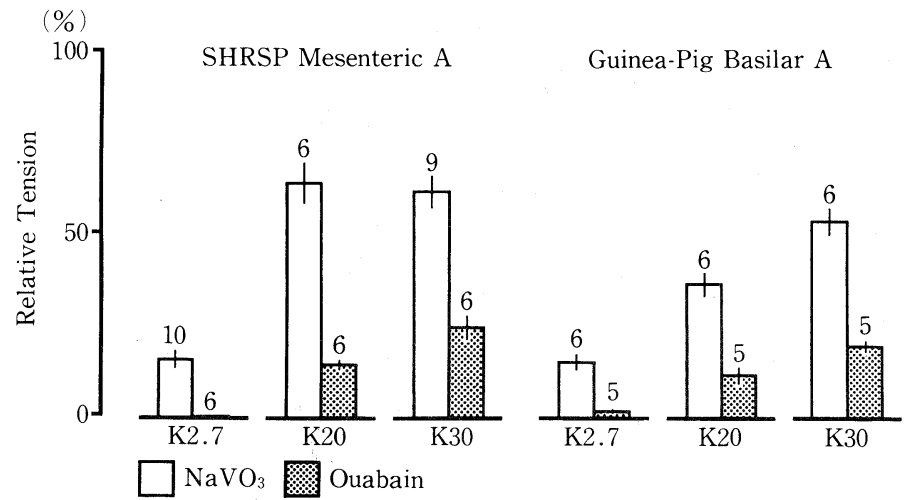

Fig. 6. Heights of sodium vanadate- and ouabain-induced contractions at different concentrations of $\mathrm{K}^{+}$. $\mathrm{K} 2.7, \mathrm{~K} 20$ and $\mathrm{K} 30$ indicate $\mathrm{K}^{+}$concentrations of $2.7 \mathrm{mM}, 20 \mathrm{mM}$ and $30 \mathrm{mM}$, respectively. Control $\mathrm{K}$-contracture height was taken as 100 percent, and each height was expressed as a percentage of this height with SEs (vertical bars). Numbers at the top of columns indicate the same as those in Fig. 4. 


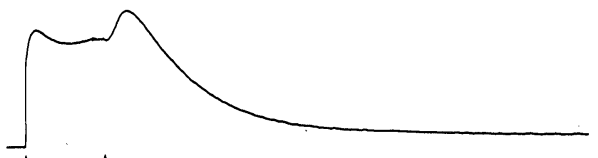

$\uparrow_{\mathrm{K} \cdot \mathrm{T}} \uparrow_{\mathrm{NaVO}_{3} 10^{-3} \mathrm{M}}$

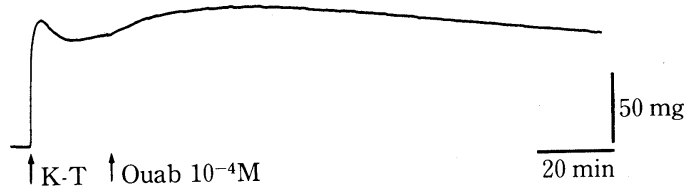

Fig. 7. Effects of sodium vanadate and ouabain on $\mathrm{K}$-depolarized preparations of the guinea-pig mesenteric artery. Either drug was applied during the course of $\mathrm{K}$ Tyrode's solution ( $\mathrm{K}-\mathrm{T}$ )-induced contracture.
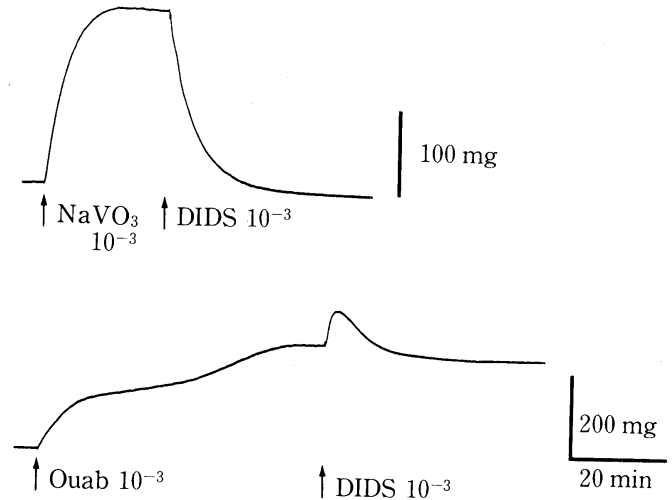

Fig. 8. Effects of DIDS on sodium vanadate- and ouabain-induced contractions of WKY aorta. $10^{-3} \mathrm{M}$ DIDS was applied at a peak of $10^{-3} \mathrm{M}$ sodium vanadate $\left(\mathrm{NaVO}_{3}\right.$ $10^{-3}$ ) or $10^{-3} \mathrm{M}$ ouabain (Ouab $10^{-3}$ )-induced contraction.

ouabain did not show any contractile action but it showed no or weak relaxing action in aorae (data was not shown).

Next, effects of DIDS, an anion transport inhibitor, on vanadate- and ouabain-induced contractions were studied. In these experiments, DIDS was applied during the course of both contractions, since it was quite difficult to obtain the ouabain-induced contraction in the absence and presence of ouabain in the same preparation, and since DIDS is also known to block the contraction when applied during vanadate-induced contraction (Shimada et al., 1986). As shown in Fig. 8, $10^{-3} \mathrm{M}$ DIDS completely relaxed $10^{-3} \mathrm{M}$ sodium vanadate-induced contraction of WKY aorta. Ouabain-induced contraction, on the other hand, was not blocked by DIDS of the same concentration, but DIDS induced a phasic contraction when aplied in the presence of ouabain. Similar blocking effects of DIDS on sodium vanadate-induced contraction were observed in the guinea-pig aorta.

\section{Effects of verapamil and Ca removal.}

Fig. 9 shows the effects of verapamil on sodium vanadate- and ouabain-induced contraction of aortae. When $10^{-5} \mathrm{M}$ verapamil was applied during the $10^{-3} \mathrm{M}$ sodium vanadateinduced contraction, marked relaxing responses were observed in WKY and SHRSP aortae. In the guinea-pig aorta, on the other hand, no change in tension was brought about by the same concentration of verapamil.

Similar results were obtained in ouabain-induced contraction of the same preparation. The ouabain-induced contractions of WKY and SHRSP aortae were relaxed by verapamil, while those of the guinea-pig aortae were not significantly influenced by verapamil.

Removal of Ca from modified Tyrode's solution abolished ouabain-induced contractions of aortae (Fig. 10). In another series of experiments, it was shown that no tension development occurred in aortae of any of the animal species examined in the absence of $\mathrm{Ca}$, even after prolonged application of ouabain up to 90 minutes. The addition of $\mathrm{Ca}$ to $\mathrm{Ca}$-free solution in 

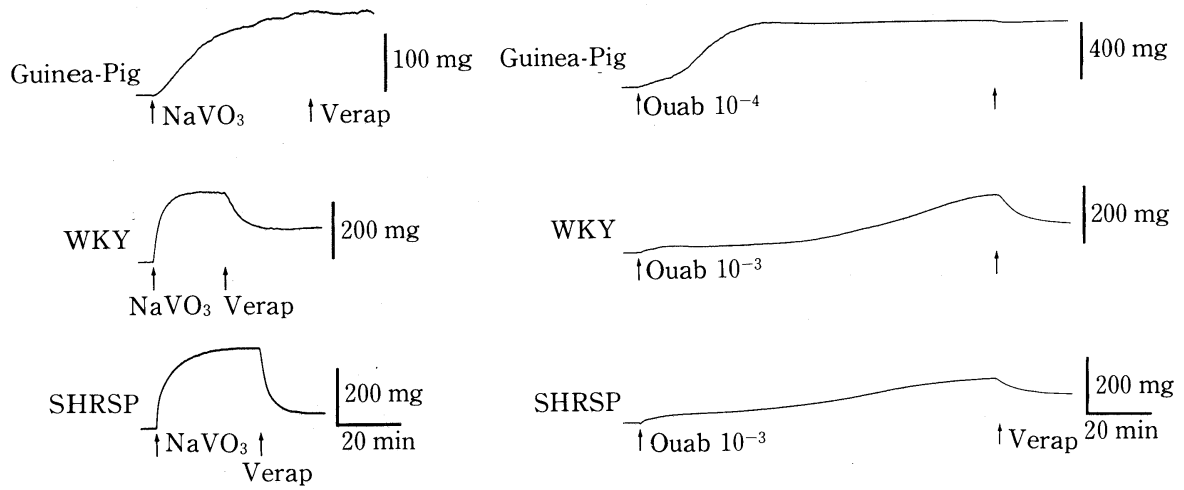

Fig. 9. Effects of verapamil on sodium vanadate- and ouabain-induced contractions of aortae of various animal species. $10^{-6} \mathrm{M}$ verapamil was applied during the course of contractions by both agents. $10^{-3} \mathrm{M}$ sodium vanadate $\left(\mathrm{NaVO}_{3}\right)$ was used in all aortae. Ouabain concentration differed in guinea-pig aortae and in WKY and SHRSP aortae, as stated in the figure (in M).
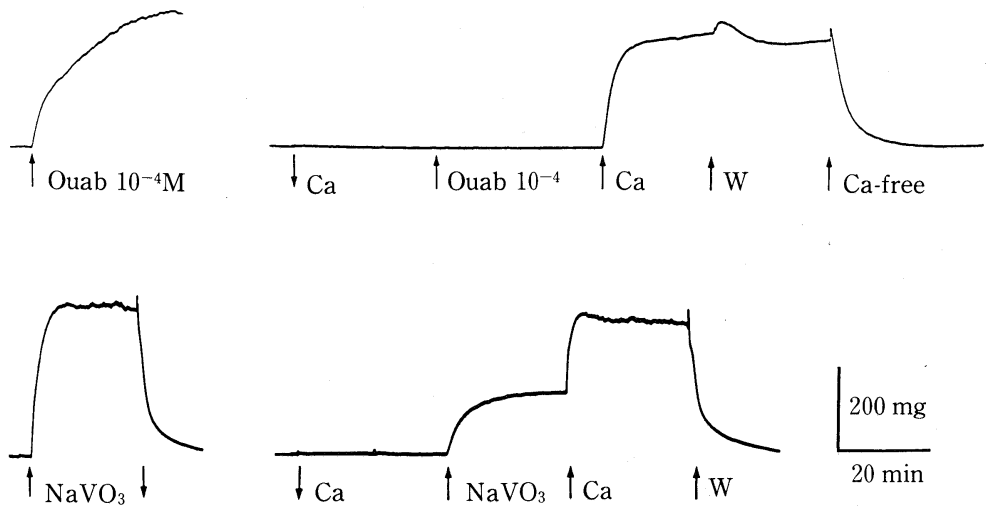

Fig. 10. Effects of Ca-removal on sodium vanadate- and ouabain-induced contractions in guinea-pig aorta. Ca with downward arrow and $\mathrm{Ca}$-free indicate the removal of $\mathrm{Ca}$ from incubation medium. Ca with upward arrow indicates the application of $2 \mathrm{mM} \mathrm{Ca}$ in the presence of ouabain $\left(10^{-4} \mathrm{M}\right)$ or sodium vanadate $\left(10^{-3} \mathrm{M}\right)$. W, washing out with modified Tyrode's solution.

the presence of ouabain caused immediate development of tension to a level similar to that of ouabain-induced contraction in the presence of $\mathrm{Ca}$. In the preparation shown in Fig. 10, the recovery after washing out of ouabain was particularly slow. The removal of Ca during the course of the recovery caused prompt relaxation of the preparation.

Ca removal also reduced vanadate-induced contraction of the aortae of all animal species tested, but it did not block the contractions completely. As shown in Fig. 10, the guinea-pig aorta responded to sodium vanadate in the absence of $\mathrm{Ca}$, showing a contraction height of about one-third that of the control sodium vanadate-induced contraction observed in the presence of Ca. The addition of $\mathrm{Ca}$ to $\mathrm{Ca}$-free Tyrode's solution in the presence of sodium vanadate induced immediate tension development to the level of the control sodium vanadate-induced contraction. Similar results were obtained in aortae of WKY and SHRSP, though the contrac- 
tions in the absence of $\mathrm{Ca}$ were markedly smaller than those of the guinea-pig aorta ; vis-ávis the dependence on extracellular Ca were greater in WKY and SHRSP aorta.

\section{Discussion}

Both vanadate and ouabain, which are known as potent inhibitors of $\mathrm{Na}, \mathrm{K}$-ATPase, induce contraction of vascular smooth muscles, as described in the introduction. It was revealed in the present experiments that these agents showed contractile actions in various types of vascular smooth muscle in a similar fashion, that is, higher contractile action in aortae of guinea-pigs, WKY and SHRSP, and lower action in the mesenteric arteries of these animals. The time to peak tension, however, differed greatly in the vanadate-induced contractions and in the ouabain-induced contractions. This may indicate some difference in the mechanism (s) of the action.

It has been reported in a certain number of vascular tissues that ouabain induces the release of noradrenaline from intrinsic sympathetic nerves (Bonaccorsi et al., 1977 ; Palatý, 1980 ; Katsuragi and Su, 1982 ; Aarhus et al., 1983; Török et al., 1984) and that the contractions by ouabain are mediated by released noradrenaline (Karaki and Urakawa, 1977 ; Karaki et al., 1978; Toda, 1980; Katsuragi and Su, 1982; Aarhus et al., 1983). However, the degree of involvement of released noradrenaline in ouabain-induced contraction varies amog types of vascular tissues (Karaki et al., 1978). In the present experiments, it was demonstrated that ouabain-induced contractions of the aortae of the guinea-pigs, WKY and SHRSP were depressed by the treatment with phentolamine. These results were inconsistent with those reported by Karaki et al. (1978), and indicated the involvement of released noradrenaline in the initiation of contraction by ouabain. Difference in the concentration of phentolamine $\left(5 \times 10^{-5}\right.$ $\mathrm{M}$ in the present experiment and $10^{-6} \mathrm{M}$ in the experiment reported by Karaki et al., 1978) and of ouabain $\left(10^{-4} \mathrm{M}\right.$ and $\left.5 \times 10^{-5}\right)$ may be the cause of the inconsistency.

The contractions of aortae of all animals by sodium vanadate, on the other hand, were not affected significantly by the treatment with phentolamine of the same concentration. This indicates that the vanadate-induced contractions of aortae are not mediated by trinsic noradrenaline. These results are in agreement with those reported in the aortae of Dahl rats (Rapp, 1981) and also in the guinea-pig aorta (Ozaki and Urakawa, 1985). Thus, it has been clarified that the major part of ouabain-induced contraction and all of vanadate-induced contraction are brought about by the direct action of these agents on vascular smooth muscles.

Vanadate has been thought to act inside smooth muscle cells, since its action was depressed by anion transport inhibitors such as DIDS or 4 acetamino-4'-isothiocyano-2, 2'-disulfonic stilbene (SITS). (Rapp, 1981; Hudgins and Bond, 1981; Ueda and Urakawa, 1983 ; Nayler and Sparrow, 1983 ; see also Schwarts and Adams, 1980). It was also demonstrated in the present experiment that DIDS blocked completely vanadate-induced contraction of the aortae of the guinea-pigs, WKY and SHRSP, while ouabain- and K-induced contractions were not blocked. Thus, it can be concluded that the effect of DIDS was not nonspecific one and that vanadate should penetrate cell membrane for the exertion of its action. It has been known that oubabin binds sites located on the surface of cell membrane (see Akera and Brody, 1978 ; Schwarts and Adams, 1980 ; Wallick et al., 1982 ; Anner, 1985). 
The potentiation of vanadate-induced contraction by depolarization in the presence of elevated-K, therefore, may be explained by increased membrane permeability to vanadate. The increase in Ca permeability by depolarization and the inhibition of extrusion or sequesteration of influxed Ca by vanadate (Wibo et al., 1981; Popesuc and Ignat, 1983; Raeymaekers et al., 1983) might also explain the potentiation by elevated $\mathrm{K}^{+}$. The elevation of $\mathrm{K}$-concentration also potentiated ouabain-induced contraction but to a lesser extent and also in a different fashion from the potentiation of vanadate-induced contraction. Unnecessity of membrane permeation for the exertion of the action, interaction with elevated- $\mathrm{K}^{+}$and inability of inhibiting $\mathrm{Ca}$ extrusion or sequesteration might account for the lesser extent of the potentiation. However, further studies are required to explain these differences.

Ouabain-induced contractions of all aortae of all animal species were abolished by the removal of extracellular Ca. Similar observations have been reported in rabbit aorta (Briggs and Shibata, 1966), dog cerebral, basilar and mesenteric arteries (Toda, 1980) and guinea-pig aorta (Ozaki et al., 1978). These may indicate that the inward movement of $\mathrm{Ca}$ is the first incidence of ouabain-induced contraction. It has also been reported in rabbit aorta that ouabain increased ${ }^{45} \mathrm{Ca}$ uptake (Briggs and Shibata, 1966). Since it has been observed in various vascular smooth muscles ihat ouabain causes depolarization of membrane (Hendrickx and Casteels, 1974 ; Casteels et al., 1977 ; Kuriyama and Suzuki, 1978 ; Reiner, 1978 ; Belardinelli et al., 1979; Mulvany et al., 1984) depolarization dependent Ca influx may occur. However, the effects of Ca-antagonist do not fully support this assumption, as will be discussed below.

Vanadate-induced contractions, on the other hand, were relatively resistant to the removal of extracellular $\mathrm{Ca}$, and contractions of the amplitudes of thirty to forty percent of the control were observed after soaking the preparations in $\mathrm{Ca}$-free solution for longer than 30 minutes. Vanadate itself does not initiate but rather depresses the contraction of skinned vascula rsmooth muscle (Shimada et al., 1986). The contraction by vanadate in the absence of extracellular $\mathrm{Ca}$, therefore, might be initiated by released $\mathrm{Ca}$ from intracellular binding sites. The part of the contraction which disappeared in the absence of $\mathrm{Ca}$, then, might be brought about by influxed $\mathrm{Ca}$ from extracellular space.

Effects of verapamil were similar in vanadate- and ouabain-induced contraction ; that is, they were ineffective in the guinea-pig aorta and effective in WKY and SHRSP aortae. Ineffectiveness of verapamil or D600 has been observed in $\mathrm{K}$-free-induced contraction (Ozaki and Urakawa, 1979) and ammonium vanadate-induced contraction (Ozaki and Urakawa, 1980) of the same smooth muscle, the guinea-pig aorta. Since verapamil has been known to block the depolarization-operated Ca channel (Fleckenstein, 1983), both the ouabain-induced and the extracellular Ca dependent part of vanadate-induced contraction of the guinea-pig aorta might be initiated by influxed $\mathrm{Ca}$ through pathways other than voltage-dependent channels. In rats, on the other hand, the major part of both ouabain- and vanadate-induced contraction might be brought about by influxed $\mathrm{Ca}$ through a potential operated $\mathrm{Ca}$ channels, though the depolarization is not expected to be as high as that induced by high-K (Hendrickx and Casteels, 1974 ; Casteels et al., 1977 ; Kuriyama and Suzuki, 1978; Reiner, 1978; Mulvany et al., 1984 for ouabain and Shimamura et al., 1986 for vanadate). 
Thus, ouabain-induced contractions of all vascular smooth muscles can be explained by the influx of $\mathrm{Ca}$ through both voltage dependent and independent $\mathrm{Ca}$ channels. The degree of contribution of both Ca channels varies among animal species. A similar explanation can be applied to vanadate-induced contractions. However, Ca released from intracellular binding sites is also involved in vanadate-induced contractions in addition to $\mathrm{Ca}$ influxed from extracellular space. The inhibition of Ca-ATPase and $\mathrm{Ca}$-uptake of sarcoplasmic reticulum reported in gastric and intestinal smooth muscle (Wibo et al., 1981; Raeymaekers et al., 1983) may be a cause of the net release of $\mathrm{Ca}$. Inhibition of $\mathrm{Ca}$-ATPase and $\mathrm{Ca}$-uptake of the sarcolemmal fraction by vanadate reported in smooth muscles (Wibo et al., 1981; Popescu and Ignat, 1983 ; Raeymaekers et al., 1983) can also be a cause of tension development inhibiting extrusion of influxed Ca.

At high concentrations, vanadate inhibits tension development of skinned preparation of hog carotid artery (Peterson, 1980) and rabbit mesenteric artery (Shimada et al., 1986). This action may be the cause of the relaxation of depolarized preparation by vanadate. Membrane permeability to vanadate might increase under the depolarized state in K-Tyrode's solution, and consequently, intracellular vanadate concentration would be increased to the level which inhibhts the contraction induced by high-K. Ouabain dose not possess such inhibiting action on contractile protein, and therefore shows no relaxing but rather contractile action increasing $\mathrm{Ca}$ influx further.

Thus, although similar potency of the action of ouabain and vanadate was observed among various types of vascular smooth muscles, it can be concluded that the mechanisms of the contractile action differ in ouabain- and in vanadate-induced contractions. Ouabain induces contraction increasing $\mathrm{Ca}$ influx, which is mediated by the inhibition of $\mathrm{Na}, \mathrm{K}$-ATPase. Vanadate, on the other hand, induces contraction both by increasing $\mathrm{Ca}$ influx and releasing intracellular bound $\mathrm{Ca}$. The inhibition of $\mathrm{Ca}$-ATPase of membrane and sarcoplasmic reticulum may be involved in the action of vanadate.

\section{References}

Aalkjaer, C. and Mulvany, M.J. (1985). Effect of ouabain on tone, membrane potential and sodium efflux compared with $\left[{ }^{3} \mathrm{H}\right]$ ouabain binding in rat resistance vessels. J. Physiol. 362: 215231.

Aarhus, L.L. et al. (1983). Contractions of canine vascular smooth muscle cells caused by ouabain are due to release of norepinephrine from adrenergic nerve endings. Circ. Res. 52: 501-507.

Akera, T. and Brody, T.M. (1978). The role of $\mathrm{Na}^{+}, \mathrm{K}^{+}-\mathrm{ATPase}$ in the inotropic action of digitalis. Pharmacol. Rev. 29: 187-220.

Anner, B.M. (1985). The receptor function of the $\mathrm{Na}^{+}, \mathrm{K}^{+}$-activated adenosine triphosphatase system. Biochem. J. 227 : 1-11.

Belardinelli, L. et al. (1979). Cardiac glycoside stimulation of inward $\mathrm{Ca}^{++}$current in vascular smooth muscle of canine coronary artery. J. Pharmacol. Exp. Ther. 209: 62-66.

Bonaccorsi, A. et al. (1977). Norepinephrine release in isolated arteries induced by $\mathrm{K}$-free solution. Am J. Physiol. 232 : H140-H145.

Briggs. A.H. and Shibata, S. (1966). Ca and ouabain interaction on vascular smooth muscle. Proc. Soc. Exp. Biol. Med. 121 : 274-278.

Broekaert, A. and Godfraind, T. (1973). The actions of ouabain on isolated arteries. Arch. int. 
Pharmacodyn. 203 : 393-395.

Cantley, L.C.Jr. et al. (1977). Vanadate is a potent (Na, K)-ATPase inhibitor found in ATP derived from muscle. J. Biol. Chem. 252: 7421-7423.

Casteels, R. et al. (1977). The membrane properties of the smooth muscle cells of the rabbit main pulmonary artery. J. Physiol. 271: 41-61.

Fleckenstein, A. (1983). Caciulm antagonism in heart and smooth muscles. John Wiley \& Sons, New York.

Grover, A.K., Jones, T.R. and Daniel, E.E. (1980). Effect of vanadate on rat myometrium plasma membrane enzyme activities. Can J. Physiol. Pharmacol. 58 : 1247-1250.

Hendrickx, H. and Casteels, R. (1974). Electrogenic sodium pump in arterial smooth muscle cells. Pflügers Arch. 346 : 299-306.

Hudgins, P.M. and Bond, G.H. (1981). Alteration by vanadate of contractility in vascular and intestinal smooth muscle preparations. Pharmacology 23 : 156-164.

Huot, S. et al. (1979). Effects of sodium vanadate $\left(\mathrm{Na}_{3} \mathrm{VO}_{4}\right)$ on wall tension and $\mathrm{Na}^{+}-\mathrm{K}^{+}$pump activity in isolated canine saphenous vein. Fed. Proc. 38: 1036

Ishida, Y. et al. (1985). Inhibitory effect of ouabain on the palytoxininduced contraction of human umbilical artery. J. Pharmacol. Exp. Ther. 232 : 557-560.

Josephson, L. and Cantley, L.C.Jr. (1977). Isolation of a potent (Na-K)-ATPase inhibitor from striated muscle. Biochemistry 16: 4572-4578.

Karaki, H., Ozaki, H. and Urakawa, N. (1978). Effects of ouabain and potassium-free solution on the contraction of isolated blood vessels. Europ. J. Pharmacol. 48: 439-443.

Karaki, H. and Urakawa, N. (1977). Possible role of endogeneous catecholamine on the contractions induced by ouabain, sodium depletion and potassium depletion in rabbit aorta. Europ. J. Pharmacol. $43: 65-72$.

Katsuragi, T. and Su, C. (1982). Release of purines and noradrenaline by ouabain and potassium chloride from vascular adrenegic nerves. Br. J. Pharmacol. 77 : 625-629.

Kuriyama, H. and Suzuki, H. (1978). The effects of acetylcholine on the membrane and contractile properties of smooth muscle cells of the rabbit superior mesenteric artery. Br. J. Pharmacol. 64: 493-501.

Moreland, R.S. et al. (1984). Functional evidence for increased sodium permeability in aortas from DOCA hypertensive rats. Hypertension 6(suppl I) I-88-I-94.

Mulvany, M.J., Aalkjaer, C. and Petersen, T.T. (1984). Intracellular sodium, membrane potential and contractility of rat mesenteric small arteries. Circ. Res. 54: 740-749.

Mulvany, M.J. et al. (1982). Potentiating and depressing effects of ouabain and potassium-free solutions on rat mesenteric resistance vessels. Circ. Res. 51 : 514-524.

Nayler, R.A. and Sparrow, M.P. (1983). Mechanism of vanadate-induced contraction of airways smooth muscle of the guinea-pig. Br. J. Pharmacol. $80: 163-172$.

Nilsson, H. and Mulavany M.J. (1981). Prolonged exposure to ouabain eliminates the greater norepinephrine-dependent calcium sensitivity of resistance vessels in spontaneously hypertensive rats. Hypertension $3:$ 691-697.

Ozaki, H., Karaki, H. and Urakawa, N. (1978). Possible role of Na-Ca exchange mechanism in the contractions induced in guinea-pig aorta by potassium free solution and ouabain. NaunynSchmiedeberg's Arch. Pharmacol. 304: 203-209.

Ozaki, H. and Urakawa, N. (1979). Na-Ca exchange and tension development in guinea-pig aorta. Naunyn-Schmiedeberg's Arch. Pharmacol. 309: 171-178.

Ozaki, H. and Urakawa, N. (1980). Effects of vanadate on mechanical responses and Na-K pump in vascular smooth muscle. Europ. J. Pharmacol. $68: 339-347$.

Palatý, V. (1980). The transient contractile response of the isolated rat tail artery to inhibition of the sodium pump. Can. J. Physiol. Pharmacol. 58: 336-339. 
Peterson, J.W. (1980). Vanadate ion inhibits actomyosin interaction in chemically skinned vascular smooth muscle. Biochem. Biophys. Res. Commun. 95 : 1846-1853.

Popescu, L.M. and Ignat, P. (1983). Calmoduline-dependent $\mathrm{Ca}^{2+}$ pump-ATPase of human smooth muscle sarcolemma. Cell Calcium $4: 219-235$.

Raeymaekers, L. et al. (1983). Isolation of a plasma-membrane fraction from gastric smooth muscle. Comparison of the calcium uptake with that in endoplasmic reticulum. Biochem. J. 210 : $315-322$.

Rapp, J.P. (1981). Aortic responses to vanadate: Independence from (Na, K)-ATPase and comparison of Dahl salt-sensitive and salt-resistant rats. Hypertension 3 (suppl I) : I-168-I-172.

Reiner, O. (1978). The role of electrogenic sodium pump in the potassium relaxation of the rabbit ear artery. Naunyn-Schmiedeberg's Arch. Pharmacol. 303 : 213-220.

Schwartz, A. and Adams, R.J. (1980). Studies on the digitalis receptor. Cire. Res. 46 (suppl I) I-154I-160.

Searle, B.M. et al. (1983). Vanadate effect on the Na, K-ATPase and the Na-K pump in in vitrogrown rat vascular smooth muscle cells. Circ. Res. 53: 186-191.

Shimada, T., Shimamura, K. and Sunano, S. (1986). Effects of sodium vanadate on various types of vascular smooth muscles. Blood Vessels 23 : 113-124.

Shimamura, K., Shimada, T. and Sunano, S. (1986). Effects of Na, K-ATPase inhibitors and Kcodnuctance inhibitors on the spontaneus contraction of portal vein from WKY and SHRSP. Jap. J. Pharmacol. $40: 122 \mathrm{P}$.

Toda, N. (1980), Mechanisms of ouabain-induced arterial muscle contraction. Am. J. Physiol. 239 : H199-H205.

Török, T. et al. (1984). Spontaoeous $\left[{ }^{3} \mathrm{H}\right]$ noradrenaline release from the main pulmonary artery of the rabbit induced by sodium-pump inhibition. Quarterly J. Exp. Physiol. 69: 841-865.

Ueda, F. et al. (1982). Dual actions of vanadate on high $\mathrm{K}$-induced contraction in guinea-pig taenia coli. Jap. J. Pharmacol. 32 : 149-157.

Ueda, F. and Urakawa, N. (1983). Influence of DIDS on the dual actions of vanadate on high Kinduced contraction in the guinea-pig taenia coli. Jap. J. Pharmacol. 33: 894-896.

Walick, E.T. et al. (1982). $\mathrm{Na}^{+}, \mathrm{K}^{+}$-ATPase of the canine mesenteric artery. Fed. Proc. 41: 21012105.

Wibo, M.Morel, N. and Godfraind, T. (1981). Differentiation of $\mathrm{Ca}^{2+}$ pumps linked to plasma membrane and endoplasmic reticulum in microsomal fraction from intestinal smooth muscle. Biochem. Biophys. Acta. 649: 651-660. 